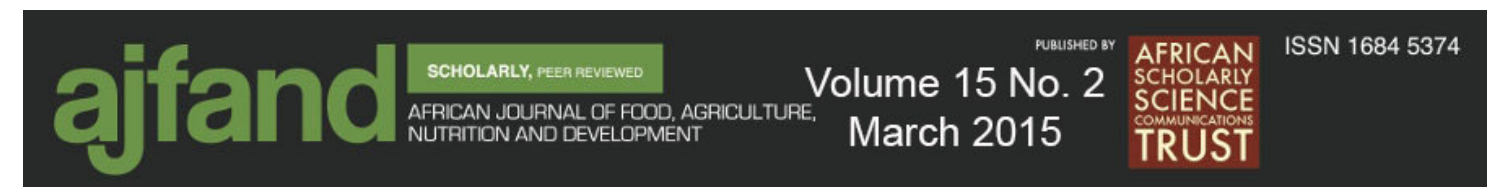

\title{
DIETARY HABITS OF A MEDITERRANEAN POPULATION OF WOMEN IN AN AGRICULTURAL REGION OF MOROCCO
}

\section{Mziwira $M^{1}$, El ayachi $M^{1}$, Lairon $D^{2}$ and $R$ Belahsen ${ }^{1 *}$}

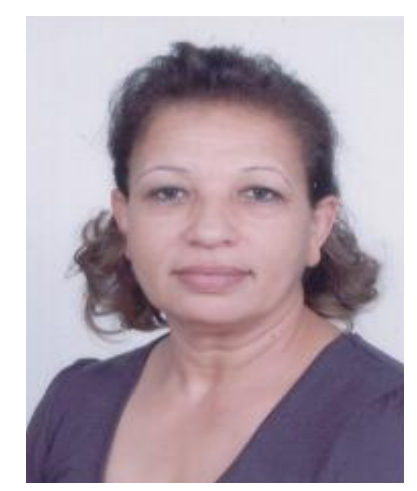

Rekia Belahsen

*Corresponding author email: rbelahsen@yahoo.com / b.rekia@gmail.com

${ }^{1}$ Laboratory of Biotechnology, Biochemistry \& Nutrition. Training and Research Unit on Nutrition \& Food Sciences. Chouaib Doukkali University. School of Sciences, El Jadida, 24000, Morocco

${ }^{2}$ INSERM, UMR476, «Nutriments Lipidiques et Prévention des Maladies Métaboliques»; INRA 1260; Univ Aix-Marseille 1 \& 2, Faculté de Médecine, IPHMIFR 125, Marseille, F-13385 France 


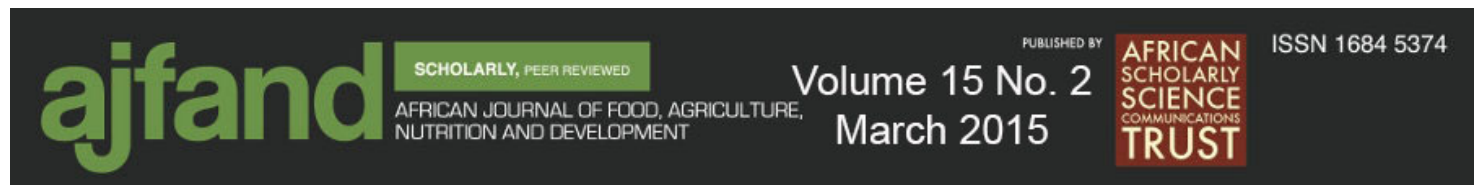

\begin{abstract}
Knowing food habits of populations is of importance to better define appropriate public health interventions. The objective of this study was to assess and describe the dietary intake and major food sources of energy and nutrients in a women sample selected from an agricultural region of Morocco. A total of 191 adult women 18-55 years old resident in urban areas in El Jadida, a costal province of Moroccowas selected. Dietary habits were assessed using a combination of a 24-h dietary recall during 3 non consecutive days and a semi-quantitative food-frequency questionnaire. Food habits are characterized by large consumption of cereals, meat and poultry, fish and sea foods, eggs, fruits and vegetables, but low intake of olive oil. The total energy intake was high and not balanced by physical activity levels. The contribution of lipids to the energy was low but high in saturated fat $(39 \%)$ reflected in the higher PUFA/SFA ratio $(0.76 \pm 0.62)$. The total carbohydrate consumption was high (61\% of daily energy) and that of fiber was low $18.07 \pm 11.44$ g. Furthermore a significantly high intake of saturated and monounsaturated fat is observed in the youngest women and women with a higher education level. Except for the intakes of phosphorus and sodium, all minerals and vitamins assessed are below or close to the recommended dietary allowance (RDA) while all vitamins are consumed at rates below two-third of RDA by a large proportion of women. The nutrient intake of the studied population is not in line with that recommended for women despite a large consumption of the majority of food groups. Data indicate that dietary guidelines should not consider only quantitative intake but must address adequate numbers of servings and favorable food choices that may explain, in part, the nutritional and metabolic disorders reported in this population.
\end{abstract}

Keywords: women, Diet - intake - habits, Mediterranean, Morocco 


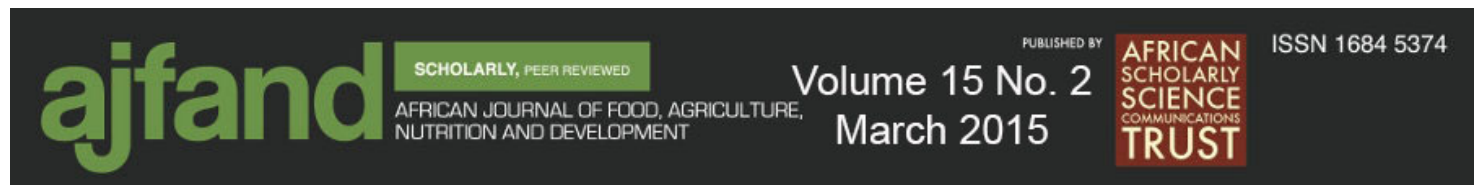

\section{INTRODUCTION}

Diet and nutrition are important factors in the promotion and maintenance of good health throughout the entire life cycle. Their role as determinants of non-communicable diseases (NCDs) is well established and they therefore occupy a prominent position in their prevention [1]. Furthermore, rapid change in diet and lifestyleoccurring with industrialization, urbanization, economic development and market globalization, were accelerated over the past decade with a significant impact on populations' health and nutritional status, particularly in developing countries and in countries in transition [2]. There is also a growing interest in the global community in galvanizing action to halt and reduce the burden of NCDs withthe aim to reverse the trend of the prevalence of premature death from NCDs. Nutrition surveillance is one of the main objectives of a Nutrition Community to establishing priorities for intervention, predicting trends and evaluating the effectiveness of nutrition interventions [3].

In Mediterranean populations, dietary habits are known to play an important role in protecting against cardiovascular disease (CVD) and in reducing effectively all-causes and cause-specific mortality rates $[4,5]$. Despite a worldwide promotion of this dietary model, epidemiological evidence suggests that dietary patterns in the Mediterranean countries are changing rapidly, with an increased consumption of animal products and saturated fat and a declined intake of foodstuffs based on fruits and vegetables [6]. This traditional dietary pattern, however, is not a homogeneous dietary mode asfood and nutritional aspects vary between countries within the Mediterranean region [7]. In Morocco, a Southern Mediterranean country with a population of more than 30 million inhabitants, the percentage of people living in urban centers has dramatically increased.Urbanization reached 55\% in 2004 and is expected to reach $62 \%$ in 2020 [8]. Non-communicable diseases are estimated to account for $75 \%$ of all deaths in which 40 $\%$ are from CVD [9]. More recent national surveys indicated that the prevalence of obesity has doubled among women, associated with diabetes, hypertension, hypercholesterolemia and CVD [10,11].

In this paper, the aim was to report dietary data regarding energy, nutrients, and food habits and, to investigate the changes in dietary intake and compare them to the dietary recommendations on one hand and the traditional Mediterranean dietary patternon the other. The influence of age and educational levels has also been evaluated.

\section{MATERIALS AND METHODS}

\section{Study sample and design}

The study was conducted on 191 urban adult women aged 18-55 years, not pregnant, living in the province of El jadida, in the northwest of Morocco, randomly selected from volunteers who visited public health centers during an immunizationcampaign. The recruitment was doneaccording to the women's age, based on data collected from a cross sectional survey in 1995 in the region of El Jadida, on women at childbearing age (1549years), which showed that the CVD risk factors were more prevalent atabout 30years. 


\section{Anthropometric and biochemical variables}

Body Mass Index (BMI) was calculated as body weight $(\mathrm{kg})$ divided by the square of height $(\mathrm{m})$ and the WHO cut-off points for obesity (BMI $>30)$ were used as measures of general obesity [12]. Plasma glucose was measured by the glucose oxidase method using a Beckman analyzer. Hyperglycemia was defined when fasting blood glucose was greater than $6.1 \mathrm{mmol} / 1$ and less than $6.9 \mathrm{mmol} / 1$, and diabetes when blood glucose was greater than $7 \mathrm{mmol} / \mathrm{l}$ [13]. Blood pressure was measured in women in a sitting position using a mercury sphygmomanometer after a rest period of at least 10 minutes. Hypertension was defined according to Adult Treatment Panel III criteria as blood pressure equal to or greater than $130 \mathrm{mmHg}$ (systolic) $/ 85 \mathrm{mmHg}$ (diastolic).

\section{Dietary data collection}

The dietary assessment methods included a combination of a $72 \mathrm{hr}$ dietary recall, collected in September and October, and a semi quantitative food - frequency questionnaire (SFFQ) to obtain the Nutrient intake and food intakes successively.

The $72 \mathrm{hr}$ recall was converted to nutrients by BILNUT (S.C.D.A. NUTRISOFTBILNUT) using a food composition database compiled and modified to accommodate the particulars of the Moroccan diet and intakes were expressed as grams per day. Nutrient intake obtained was compared to the Recommended Dietary Allowance (RDA): the average daily dietary intake level sufficient to meet the nutrient requirement of nearly all (97-98\%) healthy individuals in a particular life-stage and gender group [14].

The SFFQ included 120 food items and beverages selected, as well as questions on habitual cooking methods, to estimate the usual diet of individuals during the previous year. Standard portion sizes that included spoons, cups, bowls, glasses and a ruler were used for the estimation of consumed quantities. To obtain food intakes per day from the SFFQ, the foods in each standard portion were multiplied by the number of portions of the food consumed / week or month, divided by 7 or 30 , respectively.

As there are no Moroccan norms for dietary intake, the USDA standards were used. The study protocol was approved by the dedicated Moroccan authority of ministry of health. Each participant gave a written consent.

Statistical analyses were performed using the Statistical Package for the Social Sciences (SPSS) version 11.5 (SPSS Inc., Chicago, Illinois, USA).

\section{RESULTS}

The clinical and social characteristics of the study sample and the prevalence of abnormal values of these parameters are presented in Table 1 . The mean of age was $39.2 \pm 8.82$ years. Obesity, hypertension (defined by the cutoff point $130 / 85 \mathrm{mmHg}$ ) and diabetes were prevalent in $23,9 \%, 35,8 \%$ and $9,4 \%$ of the study population, respectively. In addition, three quarters of the population studied are illiterate, and less than one tenth are physically active. 


\section{Food groups}

Mean consumption value for each of the 11 food groups and their contribution to daily energy intake (DEI) are shown in table 2.A high consumption was observed for most food groups. There was a highconsumption of bread daily, the most frequently consumed item within the cereal group. This subgroup supplied $79 \%$ of DEI. The average of fruits intake was $192.9 \mathrm{~g} /$ day. Fruits contributed $11.5 \%$ to DEI. The fruit varieties consumed most widely by the population group included citrus fruits $(36.6 \mathrm{~g} /$ day $)$, bananas $(32.2$ $\mathrm{g}$ /day), apples (26.5 g/day) and fresh fruit juices (19.3g/day). Vegetables were mostly eaten cooked as vegetable based dishes. Milk was the most consumed dairy product (64.6 $\mathrm{g}$ /day) in which $38.3 \mathrm{~g} /$ day as pasteurized milk, followed by yoghurt ( $28.9 \mathrm{~g} /$ day $)$. A majority of the subjects $(85.7 \%)$ reported drinking milk, but only $8 \%$ whole milk. Within the meat group, beef $(48.2 \%)$ and poultry $(33.2 \%)$ were the most widely consumed foods. A high consumption of fish was observed in this population sample. The varieties most highly consumed were sardines (40.7\%), fresh anchovies $(13.6 \%)$, sole (10.4\%) and whiting (10.2\%), while all canned fishes contributed about $8.4 \%$.

\section{Energy and macronutrients}

Approximate mean daily intakes of energy and nutrients, compared to the RDA for all women arepresented in table 3. Mean daily energy was $2191.8( \pm 829.8) \mathrm{kcal}$ or $99.6 \%$ of the RDA, indicating that energy intake was just equal to the recommended values. The proportion of energy provided by Carbohydrates was too high $(60 \%$ of total energy intake) to the detriment of fat content; the diet was also high in saturated fatty acids (SFA). Reflected by the polyunsaturated /saturated fat ratio (PUFA/SFA $=0.76$ ), or by the monounsaturated/saturated fat ratio $(M U F A / S F A=1.02)$, this ratio indicate a poor consumption of plant fat particularly olive oil. The study also reports low dietary fiber and cholesterol intakes.

\section{Micronutrients}

Table 4 shows that usual intakes of phosphorus and sodium exceeded the recommended dietary allowance (RDA). This result showed that women's diet is not deficient in these nutrients. However, the mean intakes were below the RDA for dietary calcium, potassium, iron and for all vitamins assessed while they were close to RDA for magnesium and zinc. Furthermore, all vitamins are consumed at rates below three-quarts of RDA by a high percentage of women. The same observation is reported for most of the minerals ( $88 \%$ for potassium, $81,2 \%$ for calcium, $55 \%$ for iron and $43.5 \%$ for zinc) indicating that these nutrients were commonly insufficiently consumed by the women. Among the different ages (table 5), the consumption of saturated and monounsaturated fats decreased while poly-unsaturated fats and the PUFA/SFA ratio increased significantly. No age-related differences were found for all other vitamins and minerals. As shown in table 6 , the population was also stratified by education level, and the intakes were significantly lower in illiterate women (who never attended school) for Vitamin E, calcium and potassium compared to women who attended school (all education levels combined). 


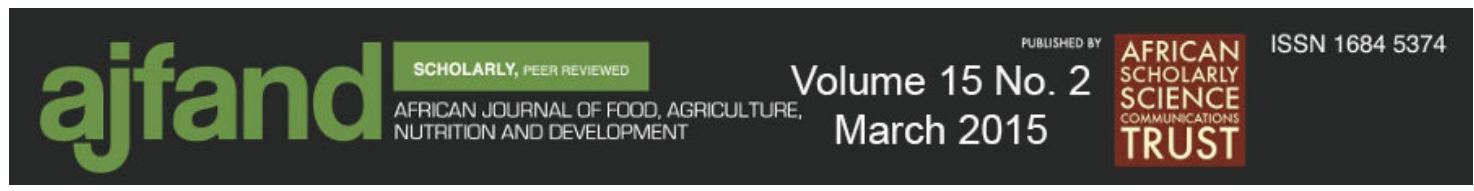

\section{DISCUSSION}

Results are presented on individuals who completed all components of a larger study that intended to characterise prevalence of CVD and associated risk factors.

Epidemiological data hasclassically demonstrated a protective effect of traditional Mediterranean dietary modelaginst CVDs $[15,16]$. This diet is characterized by: (i) high monounsaturated-to saturated fat ratio, (ii) moderate ethanol consumption, (iii) high consumption of legumes, (iv) high consumption of cereals (including bread), (v) high consumption of fruits, (vi) high consumption of vegetables, (vii) low consumption of meat and meat products and (viii) moderate consumption of milk and dairy products $[17,18]$. Most of these foods are found in many diets. The main component is olive oil, and many equate a Mediterranean diet with consumption of olive oil.

In Morocco, a developing Mediterranean country that is also experiencing demographic, health and nutritional transitions, data analysis of a survey conducted by the Ministry Of Health in 2000, showed an increased prevalence of CVD risk factors. A more recent national level survey carried out on 1500 men and women aged 15-60 years indicated also that the prevalence of obesity has doubled (17.8\%) among women, associated with diabetes (6.6\%), hypertension (33.6\%) and hypercholesterolemia (29\%)[19]. All these factors are more frequent among women than men and in urban compared to rural areas. Other studies in different country provinces confirmed the same trend $[10,12]$.

Present findings show that bread, pasta, potatoes, meat and poultry, dairy products, eggs, fruits and vegetables were the main foods eaten, and there was very low consumption of olive oil (5.5 \pm 0,7 g/day) compared to other Mediterranean studies (41.4 g/day) [20,21].

Fish consumption was particularly high, probably due to the geographic position of the study region near the Atlantic Ocean. The Economic growth of households does not necessarily decrease cereal consumption, however the consumption of animal products (mainly meat, chicken and fish) and vegetables increases. Both meats and vegetables (together or separately) are prepared as stew, a Moroccan dish locally called"tagine"prepared with oil and eaten with bread dipped in the sauce; resulting overall in high calories consumption [22].

Milk and dairy products are important contributors to dietary fat and can be high in saturated fat and cholesterol; they have been correlated positively with blood cholesterol as well as coronary mortality [23]. They are also sources of minerals like potassium, magnesium and calcium. However, in this study, consumption of milk and dairy products is not too high compared to Spain another Mediterranean country:only $8 \%$ of the Moroccan population consumed whole milk, which could explain the important deficiency in calcium and potassium intake in this population [20].

The mean consumption of fresh fruits and vegetables combined was estimated to be 304 $\mathrm{g} /$ day. Even if this intake value is approaching the WHO/FAO minimum recommended value of $400 \mathrm{~g}$ daily, it remains low despite the availability and accessibility of these products on the Moroccan market, their high national production and their relatively low 
cost [1]. This result could also explain the prevalence of the nutritional disorders reported here in the present women population. Indeed there is convincing evidence that the consumption of a diet rich in fruits and vegetables is associated with a significant low risk of CVDs, obesity, diabetes and certain types of cancer. The protective effect of these foods was reported to be probably mediated through their contents in numerous beneficial nutrients including antioxidants, vitamins, minerals, phytochemicals, fibre and plant protein $[24,25]$.

Fish is a good source of protein with no high saturated fat content of fatty meat products, is a good source of omega-3 poly-unsaturated fatty acids, reported to have beneficial effects on CVDs, diabetes and cancer. Many studies have focused on the mechanisms involved in reduction of NCDs by omega-3 fatty acids. Research has shown that omega3 fatty acids decrease the risk of arrhythmias, triglyceride levels and the growth rate of atherosclerotic plaque, and lower blood pressure slightly [26,27].

Carbohydrate intakes were higher than the recommendation certainly linked to cerealsand more sweets and dessert consumption; while that of proteins was adequate. The calories intake from fat was lower probably because of a low consumption of plant origin fat (oils, margarines, avocado, oleaginous fruits). This may also explain the low intake of certain fat-soluble vitamins (vitamin E).

There are large variations in the contribution of total fats to the energy intake in the other Southern Mediterranean Countries; the lowest is recorded in Egypt (14.5\%) and the highest in Libya (27\%). In addition, protein and carbohydrate intakes remained higher compared to all other Southern Mediterranean Countries (Egypt, Jordan, Libya, Tunisia and Algeria) [28].

Compared to the women in Northern Mediterranean Countries, fat intake reaches $39.4 \%$ in Greece, while protein intake is similar to that in Greece and in Italy (Rome and Pavia) [29].Extensive metabolic studies have investigated and reported strong and consistent associations between dietary fats and CVD in diverse human populations mediated mainly through the atherogenic effects of plasma lipids [30]. Similarly, there is evidence of the effects of dietary fats on blood pressure suggesting that reduced intake of high-fat dairy foods should be recommended for cardiovascular protection.

There is no association of CVD risks with the total quantity of fat consumed by the study population sample, as a proportion of DEI that is independent of SFA content.

This result is in agreement with the reported assumption that the type of fats consumed in the diet is more important than the total amount of fat consumed [31]. A high intake of saturated fat (38\%) was observed in the studysample. The relationship between levels of dietary saturated fat andplasma cholesterol and Coronary Heart Diseases (CHD) was already demonstrated by the Seven Countries Study, reporting that saturated fat intake explained $73 \%$ of the total variance in CHD across the 16 study cohorts [32]. Also, plasma cholesterol levels rise with dietary cholesterol [13]. In the present study, even if the cholesterol was low in the population diet it tended to increase $(260 \mathrm{mg} /$ day). In addition plasma cholesterol raising effects of SFAs is higher when combined with high cholesterol 
diets. A marked elevation of LDL cholesterol induced by dietary SFA has been demonstratedtrough metabolic studies [33]. The major sources of cholesterol are Dairy fat and meat. Egg yolk is particularly rich in cholesterol but unlike dairy and meat does not provide saturated fatty acids (SFAs).

It is importantto note the high intake of Mono-unsaturated fats related to exclusive consumption of fresh cooked food, oleaginous fruits, high fat fruits such avocados, corn and sunflower oil, despite the small proportion of olive oil in fat and oils food group. Mono-unsaturated fats have been shown to lower blood glucose and triglycerides in type II diabetics and may decrease susceptibility of LDL to oxidative modification.

The data support the need to emphasize low saturated fat, low added sugar, low meat options when helping women make food choices, such as encouraging consumption of fruit, vegetables, milk and milk products, and the return to traditional foods (whole grain cereals, olive oil and traditional methods of preparing food at home. Promoting the traditional Mediterranean diet would be the best mean to ameliorate the population's nutritional profile.

Carbohydrates provide the required energy for the body performance, for the brain, andto burn fats [34]. The relationship between dietary carbohydrates and CVD appears to be mediated through their contribution to total energy and link with obesity, effects on plasma lipids, and effects on insulin resistance and glucose disposal [35, 36]. Another group of dietary components is dietary fiber generally derived from fruits, vegetables and whole grains; cereals are the major source, presenting only two third of RDA. High fiber diets have received considerable attention in recent years, due to their connection with lower incidence of several metabolic disorders such as blood pressure, diabetes, obesity, as well as heart disease and colon cancer [37].

On the other hand, except for phosphorus and sodium intakes, the intakes of minerals and vitamins were inadequate in the studied women. The vitamins that are necessary for normal metabolism are manufactured in the green leaves and plant roots except for vitamin B-12 that is mainly found in animal foods and products. It is a fact that vitamin deficiency leads to poor health and even death. Folate deficiency may generate anaemiaandfoetal neural tube defects $[38,39]$. Low zinc intake is also known to enhance the risk of pre-term delivery, low weight at birth and immune dysfunction [40].

In this population, there was a high overall prevalence of hypertension $(35.8 \%)$ accompanied by excessive usual intakes of sodium (187.1\%) that is almost double the RDA. Generally, excessive consumption of salt causes hypertension in many people or aggravates existing hypertension.Current evidence suggests that an intake of $1.7 \mathrm{~g}$ of sodium (equivalent to a daily sodium chloride intake of $4 \mathrm{~g} / \mathrm{d}$ ) is beneficial in reducing blood pressure and is not associated with adverse effects [41].

On the other hand, iron intake requirements are not met in the present population diet where they were were below the RDA (84.1\%). The adverse effects of iron deficiency induced anemia are known for the mother (tiredness, reduced physical and mental performance, and reduced immune function) as well as for the fetus (prematurity, low 


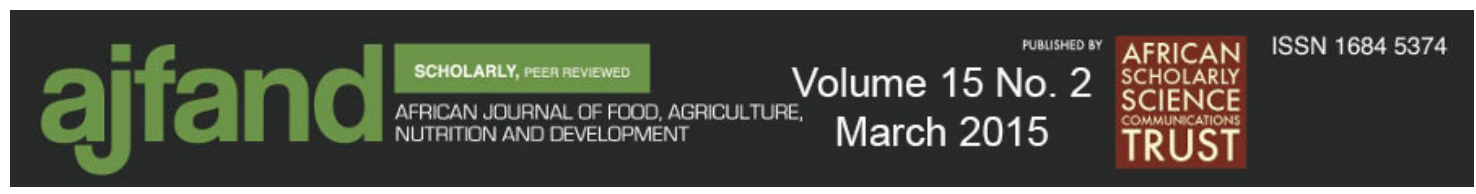

birth weight and infection) [42]. Educational efforts are also needed to provide adequate information on how to achieve an optimum diet that meets the recommendations and the requirements for all these micronutrients.

\section{CONCLUSION}

Overall, the study data revealed that the nutrient intake of the studied population is not in line with that recommended for women, also there is a shift from the traditional diet. Adoption of new dietary habits and changes in lifestyle by promoting adherence to traditional Mediterranean dietary pattern that could bring adequate nutrient intake is recommended to prevent the nutritional and metabolic disorders that are prevalent in this study population.

\section{Acknowledgements:}

This study has been carried out with the financial support (Joint grant) of INSERM (Institut National de la Santé et de la Recherche Medicale, France) and CNCPRST (Centre National de Coopération et de Recherche Scientifique, Morocco). 


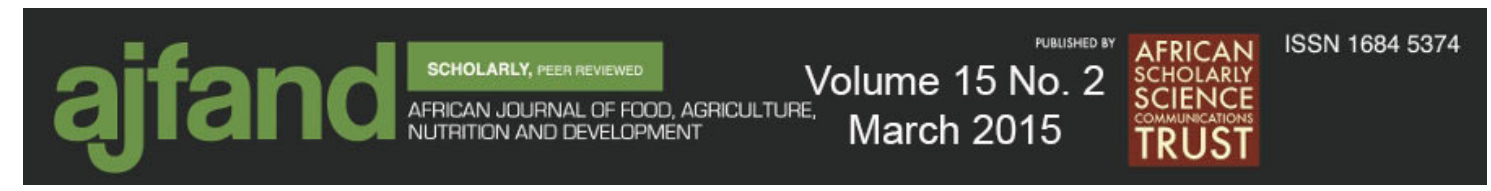

Table1: Clinical and social characteristics of the participants inthe dietary survey

\begin{tabular}{|c|c|c|}
\hline & $\begin{array}{l}\text { Mean } \\
( \pm \text { sd })\end{array}$ & Abnormal values $(\%)$ \\
\hline AGE (years) & $39,2 \pm 8.82$ & \\
\hline Body Mass Index (kg/m2) & $26.46 \pm 4.87$ & \\
\hline Obesity $(\%)$ & & 23.9 \\
\hline Systolicblood pressure (mmHg) & $122.04 \pm 13.99$ & \\
\hline Diastolicblood pressure $(\mathrm{mmHg})$ & $73.03 \pm 8.38$ & \\
\hline Hypertension $(\%)$ & & 35.8 \\
\hline Fasting plasma glucose $(\mathrm{mmol} / \mathrm{l})$ & $0.86 \pm 0.46$ & \\
\hline Hyperglycemia $(\%)$ & & 14.6 \\
\hline Diabetes $(\%)$ & & 9.4 \\
\hline Physical activity Yes & & 6.6 \\
\hline No & & 93.4 \\
\hline \multicolumn{3}{|l|}{ Educational level } \\
\hline Attended school & $24.6 \%$ & \\
\hline Never attended school & $75.4 \%$ & \\
\hline
\end{tabular}




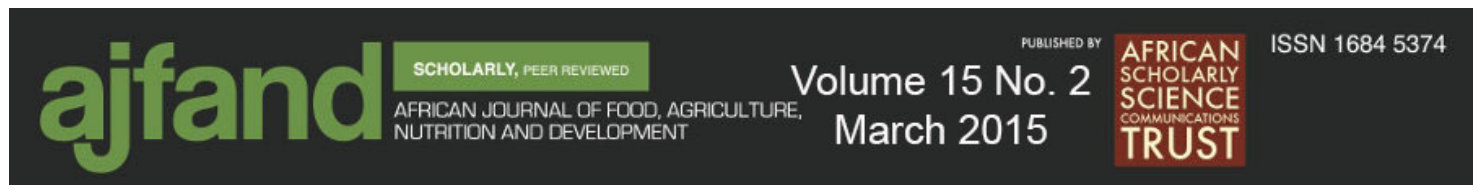

Table 2: Mean consumption values, percentage of consumers and contribution of each food group to energy intake in the total study population aged 18-55 years $(n=$ 191)

\begin{tabular}{|c|c|c|c|}
\hline Food group & Consumption (g/day) & $\begin{array}{c}\% \text { of consumers } \\
\text { and (Contribution } \\
\text { to energy intake } \\
(\%))\end{array}$ & $\begin{array}{l}\% \text { of food } \\
\text { in the } \\
\text { same food } \\
\text { group }\end{array}$ \\
\hline Cereals & $696.4 \pm 396.8(638.3-754.4)$ & $100(41.6)$ & \\
\hline Bread & & & 79.0 \\
\hline Pasta & & & 5.0 \\
\hline Couscous & & & 6.0 \\
\hline Other & & & 10.0 \\
\hline Meat and poultry & $103.5 \pm 72,4(92.9-114.1)$ & $98.9(6.1)$ & \\
\hline Red meat & & & 66.8 \\
\hline Poultry & & & 33.2 \\
\hline Fish and seafood & $58.2 \pm 70.6(47.9-68.5)$ & $93.4(3.4)$ & \\
\hline Sardines & & & 40.7 \\
\hline Anchovies, whit & & & 24.5 \\
\hline canned fishes & & & 8.4 \\
\hline Other & & & 26.4 \\
\hline Dairy products & $140.1 \pm 133.1(120.7-159.6)$ & $99.5(8.3)$ & \\
\hline Milk & & & 46.1 \\
\hline yogurt & & & 20.6 \\
\hline Cheese & & & 7.2 \\
\hline Other & & & 25.8 \\
\hline Eggs & $32.9 \pm 28,9(28.62-37.1)$ & $90.7(1.9)$ & \\
\hline Fruits & $192.9 \pm 134.7(173.2-212.6)$ & $99.5(11.5)$ & \\
\hline citrus fruits & & & 19.0 \\
\hline Bananas & & & 16.7 \\
\hline Apples & & & 13.7 \\
\hline melon,apricot,tomatoes & & & 50.6 \\
\hline $\begin{array}{l}\text { Vegetables: onion, } \\
\text { carrot,Turnip, salad, } \\
\text { eggplant... }\end{array}$ & $111.1 \pm 67.2(101.2-120.8)$ & $98.4(6.6)$ & \\
\hline $\begin{array}{l}\text { Legumes (lentils , Dry } \\
\text { beans....) }\end{array}$ & $29.8 \pm 2.4(25.2-34.5)$ & $72.5(1.8)$ & \\
\hline Potatoes & $120.5 \pm 85.5(108.0-133.1)$ & $94.5(4.0)$ & \\
\hline Sweets and desserts & $22.6 \pm 2.2(18.3-26.9)$ & $75.0(1.3)$ & \\
\hline Fat and oil & $31.1 \pm 1.75(27.7-34.6)$ & $97.3(1.8)$ & \\
\hline Fat & & & 10.1 \\
\hline Butter & & & 16.3 \\
\hline Olive oil & & & 17.6 \\
\hline Other Vegetable oils & & & 56.0 \\
\hline (Sunflower, argane...) & & & \\
\hline
\end{tabular}




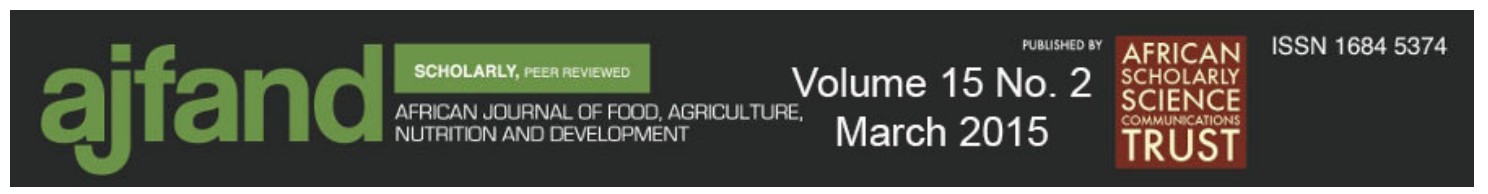

Table 3: Mean daily energy and macronutrient intake in the total study population

\begin{tabular}{lcc}
\hline Nutrients (recommendations) & $\begin{array}{c}\text { Intake } \\
(\text { mean } \pm \text { SD) }\end{array}$ & $\begin{array}{c}\text { \%of } \\
\text { recommendations }\end{array}$ \\
\hline${\text { Energy }(2200 \mathrm{kcal})^{\mathrm{a}}}^{\mathrm{a}}$ & $2191.8 \pm 829.8$ & $99.6 \%$ \\
${\text { Carbohydrates }(130 \mathrm{~g})^{\mathrm{a}}}^{\text {Proteins }(46 \mathrm{~g})^{\mathrm{a}}}$ & $333.80 \pm 145$ & $256.8 \%$ \\
Fat & $81.98 \pm 79.9$ & $178.2 \%$ \\
\% of energy from & $62.61 \pm 33.6$ & - \\
$\quad$ & & \\
$\quad$ Carbohydrates $(42 \%)^{\mathrm{b}}$ & $60 \pm 9.9$ & $142.8 \%$ \\
$\quad$ Proteins $(15 \%)^{\mathrm{b}}$ & $14.28 \pm 2.6$ & $95.2 \%$ \\
$\quad$ Fat (42\%) & $25,42 \pm 8.95$ & $60.5 \%$ \\
\% of energy from total fat intake & & \\
$\quad$ SFA & $38.6 \pm 9.94$ & \\
$\quad$ MUFA & $37.03 \pm 7.5$ & \\
PUFA & $24.37 \pm 12.93$ & \\
PUFA/SFA & $0.76 \pm 0.62$ & $86.7 \%$ \\
MUFA/SFA & $1.02 \pm 0.35$ & $66.9 \%$ \\
Cholesterol (300mg) & \\
Dietary fiber(27g) & &
\end{tabular}

\footnotetext{
${ }^{a}$ RDA: Institute of Medicine, National Academies. Food and Nutrition Board. Recommended Dietary Allowance, 2010. ${ }^{\mathrm{b}}$ Trichopoulo et al [43].
} 


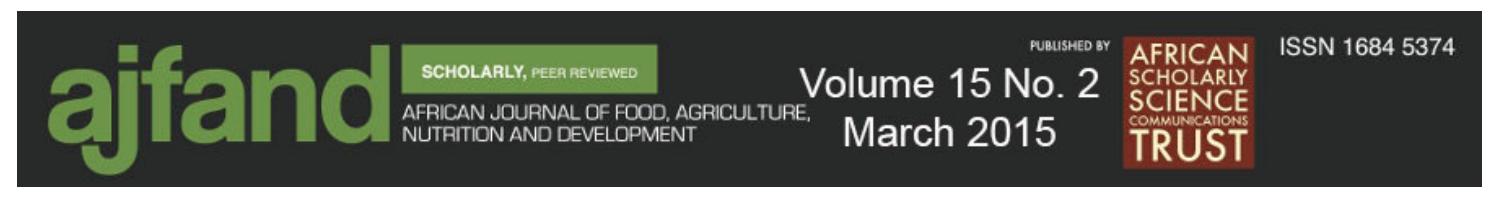

Table 4: Mean daily micronutrient intake in the total study population

\begin{tabular}{|c|c|c|c|c|c|}
\hline \multirow[t]{2}{*}{ Nutrients (RDA) } & \multirow{2}{*}{$\begin{array}{c}\text { Intake } \\
(\mathrm{mean} \pm \mathrm{SD})\end{array}$} & \multirow[t]{2}{*}{$\%$ of RDA } & \multicolumn{3}{|c|}{$\%$ of the sample } \\
\hline & & & $<75 \%$ RDA & $75-100 \%$ RDA & $>100 \%$ RDA \\
\hline \multicolumn{6}{|l|}{ Vitamins: } \\
\hline Vitamin E (15mg) & $3.74 \pm 0.4$ & $24.9 \%$ & 95.8 & 1.1 & 3.1 \\
\hline Vitamin C (75mg) & $60.65 \pm 51$ & $80.86 \%$ & 58.1 & 15.7 & 26.2 \\
\hline Vitamin B1 (1.1mg ) & $0.95 \pm 0.39$ & $86.4 \%$ & 42.4 & 30.4 & 27.2 \\
\hline Folates $(400 \mu \mathrm{g})$ & $328.48 \pm 24.18$ & $82.1 \%$ & 62.3 & 15.7 & 22 \\
\hline \multicolumn{6}{|l|}{ Minerals: } \\
\hline Sodium(1500mg) & $2806.92 \pm 128.65$ & $187.1 \%$ & 18.3 & 8.4 & 73.3 \\
\hline Calcium(1000mg) & $515.39 \pm 344.2$ & $51.5 \%$ & 81.2 & 9.4 & 9.4 \\
\hline Potassium(4700mg) & $2431.52 \pm 1130.9$ & $51.7 \%$ & 88 & 6.8 & 5.2 \\
\hline Magnesium(310-320mg) & $301.48 \pm 137.49$ & $94.2 \%$ & 33 & 31.4 & 35.6 \\
\hline Phosphorus(700mg) & $1245.43 \pm 508.25$ & $177.9 \%$ & 3.1 & 8.9 & 88 \\
\hline Iron(18mg) & $15.14 \pm 13.4$ & $84.1 \%$ & 55 & 21.4 & 23.6 \\
\hline Zinc(8mg) & $7.55 \pm 3.91$ & $94.4 \%$ & 43.5 & 21.9 & 34.6 \\
\hline
\end{tabular}

RDA: Institute of Medicine, National Academies. Food and Nutrition Board. Recommended Dietary Allowance, 2010. 


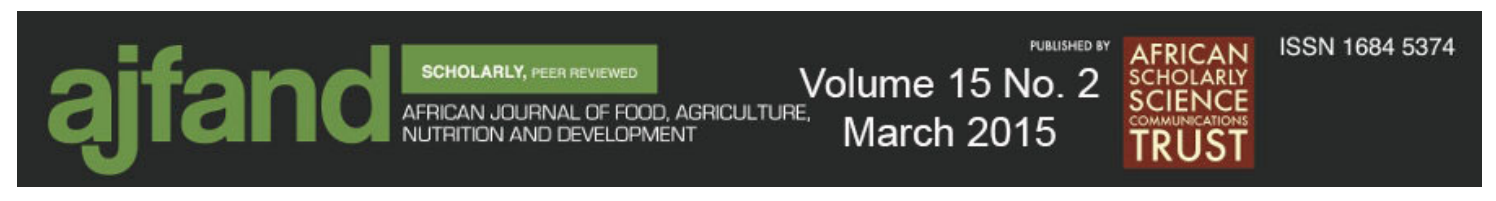

Table5: Nutrient daily intake in women according to age

\begin{tabular}{|c|c|c|c|c|}
\hline & $\begin{array}{c}<35 \text { years } \\
(n=53)\end{array}$ & $\begin{array}{c}35-44 \text { years } \\
(n=63)\end{array}$ & $\begin{array}{c}\geq 45 \text { years } \\
(n=75)\end{array}$ & P-value \\
\hline Energy(kcal/day) & $2175.1 \pm 870,2$ & $2268.6 \pm 898.3$ & $2139.0 \pm 742.7$ & NS \\
\hline Carbohydrates (\%) & $62.5 \pm 8,6$ & $58.9 \pm 9.4$ & $59.1 \pm 10.9$ & NS \\
\hline $\operatorname{saccharose}(\%)$ & $2.4 \pm 0,8$ & $1.35 \pm 0.2$ & $0.9 \pm 0.2$ & 0.035 \\
\hline Proteins $(\%)$ & $14,2 \pm 2,4$ & $14.1 \pm 2.8$ & $14.3 \pm 2.6$ & NS \\
\hline Fat $(\%)$ & $23.3 \pm 8.3$ & $27.0 \pm 8.6$ & $25.5 \pm 9.4$ & NS \\
\hline SFA (\%) & $41.9 \pm 10.1$ & $38.7 \pm 9.8$ & $36.2 \pm 9.3$ & 0.013 \\
\hline MUFA (\%) & $38.82 \pm 6.9$ & $37.6 \pm 7.9$ & $35.3 \pm 7.2$ & 0.023 \\
\hline PUFA (\%) & $19,2 \pm 12.1$ & $23.7 \pm 12.7$ & $28.5 \pm 12.4$ & 0.000 \\
\hline PUFA/SFA & $0.6 \pm 0.5$ & $0.7 \pm 0.5$ & $0.9 \pm 0.6$ & 0.006 \\
\hline MUFA/SFA & $0.99 \pm 0.3$ & $1.03 \pm 0.3$ & $1.03 \pm 0.3$ & NS \\
\hline Cholesterol (mg) & $205,5 \pm 22,17$ & $266.5 \pm 47.0$ & $292.9 \pm 34.4$ & NS \\
\hline Dietary fiber(g) & $17,5 \pm 12,63$ & $17.7 \pm 11.8$ & $18.8 \pm 10.3$ & NS \\
\hline \multicolumn{5}{|l|}{ Vitamins: } \\
\hline Vitamin E (mg) & $2.5 \pm 0.3$ & $3.8 \pm 0.7$ & $4.6 \pm 0.7$ & NS \\
\hline Vitamin C (mg ) & $58,1 \pm 48,8$ & $62.7 \pm 55.8$ & $60.6 \pm 48.8$ & NS \\
\hline Vitamin B1 (mg) & $0,98 \pm 0.45$ & $0.9 \pm 0.3$ & $0.9 \pm 0.3$ & NS \\
\hline Folates $(\mu \mathrm{g})$ & $247,3 \pm 17,5$ & $326.4 \pm 32.4$ & $387.5 \pm 53.1$ & NS \\
\hline \multicolumn{5}{|l|}{ Minerals: } \\
\hline Sodium(mg) & $2501,9 \pm 234,3$ & $2911.2 \pm 235.0$ & $2934.8 \pm 202.0$ & NS \\
\hline Calcium(mg) & $519,7 \pm 284,2$ & $520.4 \pm 306.7$ & $508.0 \pm 410.5$ & NS \\
\hline Potassium(mg) & $2550,5 \pm 1245,8$ & $2478.9 \pm 1134.0$ & $2307.5 \pm 1043.0$ & NS \\
\hline Magnesium(mg) & $302,3 \pm 161,1$ & $301.6 \pm 142.5$ & $300.7 \pm 115.2$ & NS \\
\hline Phosphorus(mg) & $1210,5 \pm 525,9$ & $1290.4 \pm 532.5$ & $1232.3 \pm 477.9$ & NS \\
\hline $\operatorname{Iron}(\mathrm{mg})$ & $15,7 \pm 2,7$ & $14.5 \pm 10.3$ & $15.2 \pm 9.5$ & NS \\
\hline Zinc(mg) & $7,2 \pm 4,2$ & $8.1 \pm 4.2$ & $7.2 \pm 3.4$ & NS \\
\hline
\end{tabular}




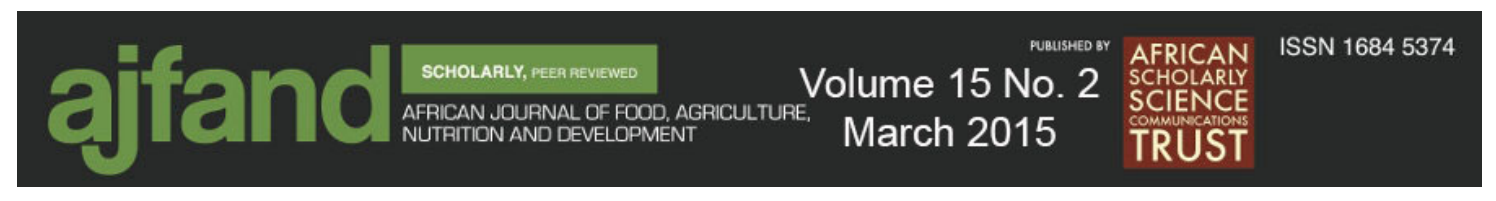

Table 6: Nutrient daily intake in women according to Education level adjusted for age

\begin{tabular}{|c|c|c|c|c|}
\hline & $\begin{array}{c}\text { Intake } \\
(\text { mean } \pm \text { SD })\end{array}$ & $\begin{array}{l}\text { Never attended school } \\
\qquad(\mathrm{n}=47)\end{array}$ & $\begin{array}{l}\text { attended school } \\
\quad(\mathrm{n}=144)\end{array}$ & P-value \\
\hline \multicolumn{5}{|l|}{ Vitamins: } \\
\hline Vitamin E (mg) & $3.74 \pm 0.4$ & $3,1 \pm 0,5$ & $3,9 \pm 0,5$ & 0.025 \\
\hline Vitamin C (mg) & $60.65 \pm 51$ & $52,3 \pm 6,3$ & $63,3 \pm 4,4$ & NS \\
\hline Vitamin B1(mg) & $0.95 \pm 0.39$ & $0,8 \pm 0,3$ & $1,0 \pm 0,4$ & NS \\
\hline Folates $(\mu \mathrm{g})$ & $328.48 \pm 24.18$ & $313,6 \pm 27,9$ & $333,3 \pm 30,8$ & NS \\
\hline \multicolumn{5}{|l|}{ Minerals: } \\
\hline Sodium(mg) & $2806.92 \pm 128.65$ & $2879,8 \pm 210,6$ & $2783,1 \pm 156,5$ & NS \\
\hline Calcium(mg) & $515.39 \pm 344.2$ & $403,7 \pm 212,2$ & $551,8 \pm 370,8$ & 0.037 \\
\hline Potassium(mg) & $2431.52 \pm 1130.9$ & $1917,8 \pm 788,1$ & $2599,1 \pm 1176,6$ & 0.001 \\
\hline Magnesium(mg) & $301.48 \pm 137.49$ & $276,8 \pm 106,2$ & $309,5 \pm 145,7$ & NS \\
\hline Phosphorus(mg) & $1245.43 \pm 508.25$ & $1095,6 \pm 327,1$ & $1294,3 \pm 546,9$ & NS \\
\hline $\operatorname{Iron}(\mathrm{mg})$ & $15.14 \pm 13.4$ & $11,0 \pm 4,4$ & $16,5 \pm 15,0$ & NS \\
\hline Zinc(mg) & $7.55 \pm 3.91$ & $7.19 \pm 3.2$ & $7,7 \pm 4.1$ & NS \\
\hline
\end{tabular}




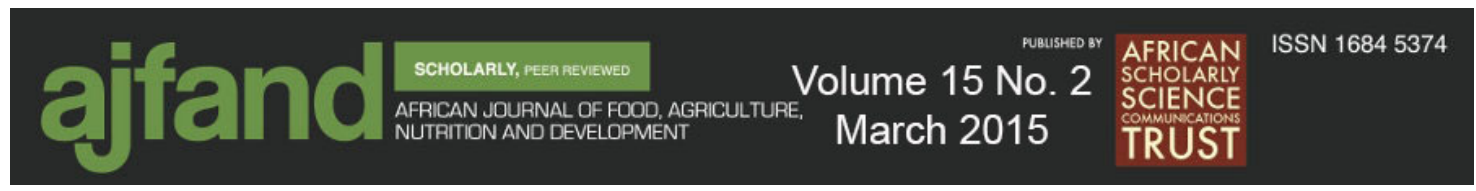

\section{REFERENCES}

1 World Health Organization (WHO) Diet, Nutrition and the Prevention of ChronicDisease. 2003. WHO, Geneva, Switzerland.

2 World Health Organization (WHO) Globalization, diets and noncommunicable diseases. 2002. WHO, Geneva, Switzerland.

3 World Health Organization (WHO) NutrientProfiling. 2010. WHO, Geneva, Switzerland.

4 Sofi F, Abbate R, Gensini GF and A Casini Accruing evidence on benefits of adherence to the Mediterranean diet on health: an updated systematic review and metaanalysis. Am J Clin Nutr 2010; 92: 1189-1196.

5 Martinez-Gonzalez MA, Bes-Rastrollo M, Serra-Majem L, Lairon D, Estruch $\mathbf{R}$ and $\mathbf{A}$ Trichopoulou Mediterranean food pattern and the primary prevention of chronic disease: recent developments.Nutr Rev2009; 67: S111S116.

6 Tur JA, Romaguera $D$ andA Pons Food consumption patterns in a Mediterranean region: does the Mediterranean diet still exist? Ann NutrMetabol 2004; 48: 193-201.

7 Matalas ALDisparities within traditional Mediterranean food patterns: an historical approach of the Greek diet. Int J Food Sci Nutr; 2006; 57: 529-536.

8 Centre d'Etudes et de Recherches Démographiques (CERED) Taux d'urbanisation par année: 1960 - 2050. L'Enquête nationale démographique 2009-2010. 2010.

9 World Health Organization (WHO) Noncommunicable diseases country profiles, WHO global report 2011. WHO, Geneva, Switzerland.

10 Belahsen R, Bermudez OI, Mziwira M, Fertat F, Newby PK and KL Tucker Obesity and related metabolic disorders are prevalent in Moroccan women of child-bearing age. Int J Diabetes Metabol 2005; 13:159-166.

11 Rguibi M andR Belahsen Overweight and obesity among urban Sahraoui women of south Morocco. Ethn Dis 2004; 14:542-547.

12 Mziwira M, El Ayachi M, Lairon D and R Belahsen High blood pressure in urban Moroccan women from an agricultural region. Mediterr $J$ Nutr Metab 2010; 1-6. 
13 National Cholesterol Education Program (NCEP) Executive summary of the third report of the National Cholesterol Education Program expert panel on detection, evaluation, and treatment of high blood cholesterol in adults (Adult Treatment Panel III). JAMA 2001; 285: 2486-2497.

14 Murphy S andMI Poos Dietary Reference Intakes: summary of applications in dietary assessment. Public Health Nutr2002; 5: 843-849.

15 Giugliano D andK Esposito Mediterranean diet and metabolic diseases. CurrOpinLipidol2008;19: 63-8.

16 Salas-Salvadó J, Bulló M, Babio N, Martínez-González MÁ, IbarrolaJurado N, Basora J, Estruch R, Covas MI, Corella D, Aros F, Ruiz-Gutiérrez $\mathbf{V}$ and $\mathbf{E}$ Ros Reduction in the incidence of type 2 diabetes with the Mediterranean Diet: Results of the PREDIMED-Reus Nutrition Intervention Randomized trial. Diabetes Care 2011; 34:14-9.

17 Sofi F, Cesari F and A Casini Adherence to Mediterranean diet and health status: meta-analysis. BMJ 2008; 337: a1344.

18 Trichopoulou A, Kouris-Blazos A, Vassilakou T, Gnardellis Ch, Polychronopoulos E, Venizelos M, Lagiou P, Wahlqvist ML \& Trichopoulos D The diet and survival of elderly Greeks: A link to the past. Am J Clin Nutr 1995; (61S):1346-1350.

19 Tazi MA, Abir-Khalil S, Chaouki N, Cherquaoui S, Lahmouz F, Srairi JE and $\mathbf{J}$ Mahjour Prevalence of the main cardiovascular risk factors in Morocco: results of a National Survey, 2000. J Hypertens 2003 ; 21: 897-903.

20 Varela-Moreiras G, Avila JM, Cuadrado C, S del Pozo, E Ruiz and O Moreiras Evaluation of food consumption and dietary patterns in Spain by the Food Consumption Survey: updated information. Eur JClinNutr 2010; 64: S37S43.

21 Barbagallo CM, Cavera G, Sapienza M Noto D, Cefalù AB, Polizzi F, Onorato F, Rini G, Di Fede G, Pagano M, Montalto G, Rizzo M, Descovich G, Notarbartolo A and MR Averna Nutritional Characteristics of a Rural Southern Italy Population: The Ventimiglia di Sicilia Project. $J \mathrm{Am}$ CollNutr2002; 21: 523-529.

22 Benjelloun S Nutrition transition in Morocco. Public Health Nutr 2002; 5: 135140.

23 Ascherio A Epidemiological studies on dietary fats and coronary heart disease. Am J Med 2002; 113: 9S-12S. 


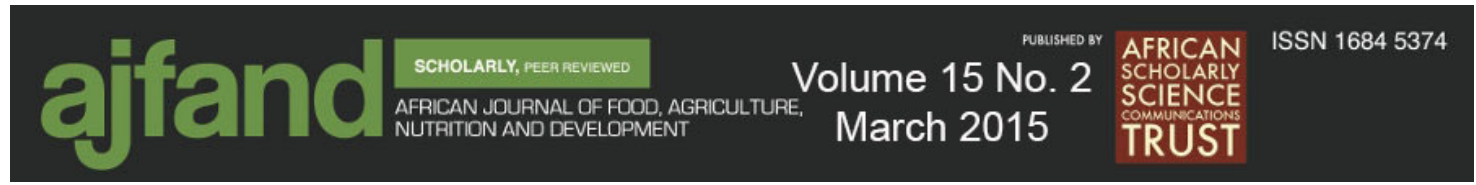

24 Tang L, Zirpoli GR, Guru K Moysich KB, Zhang Y, Ambrosone CB, and SE McCann Consumption of raw cruciferous vegetables is inversely associated with bladder cancer risk. Cancer Epidemiol Biomarkers Prev2008; 17: 938-944.

25 Pitsavos C, Panagiotakos DB, Tzima N, Chrysohoou C, Economou M, Zampelas A and C StefanadisAdherence to the Mediterranean diet is associated with total antioxidant capacity in healthy adults: the ATTICA study. $\mathrm{Am} \mathrm{J}$ ClinNutr 2005; 82: $694-699$.

26 Simopoulos AP Evolutionary aspects of diet, the omega-6/omega 3-ratio and genetic variation. Biomed Pharmacother 2006; 60: 502-507.

27 Poudyal H, Panchal SK, Diwan V and L BrownOmega-3 fatty acids and metabolic syndrome: effects and emerging mechanisms of action. Prog Lipid Res2011; 50: 372-87.

28 Food and Agriculture Organizations of the United Nations (FAO) 2010; Nutrition \& consumer protection. http://www.fao.org/ag/agn/nutrition/profiles by country fr.stm. Accessed 25 December 2010.

29 Karamanos B, Thanopoulou A, Angelico F, Assaad-Khalil S, Barbato A, Del Ben M, Dimitrijevic-Sreckovic V, Djordjevic P, Gallotti C, Katsilambros N, Migdalis I, Mrabet M, Petkova M, Roussi D andMT Tenconi Nutritional habits in the Mediterranean Basin. The macronutrient composition of diet and its relation with the traditional Mediterranean diet, Multi-centre study of the Mediterranean Group for the Study of Diabetes (MGSD) Eur J ClinNutr2002; 56: $983-991$.

30 Kris-Etherton P, Daniels SR and RH Eckel Total cholesterol, lipoprotein fractions and triglycerides, for the Nutrition Committee of the American Heart Association, Summary of the Scientific Conference on Dietary Fatty Acids and Cardiovascular Health. Circulation 2001; 103: 1034-9.

31 Hu FB, Manson JE andWC Willett Types of dietary fat and risk of coronary heart disease: a critical review. J Am CollNutr 2001; 20: 5-19.

32 Skeaff CM and J Miller Dietary Fat and Coronary Heart Disease: Summary of evidence from prospective cohort and randomised controlled trials. Ann NutrMetab 2009; 55: 173-201.

33 Elmadfa I andM Kornsteiner Fats and fatty acid requirements for adults. Ann NutrMetab 2009; 55: 56-75.

34 Panagiotakos DB andE Polychronopoulos The role of Mediterranean diet in the epidemiology of metabolic syndrome; converting epidemiology to clinical practice. Lipids Health Dis 2005; 12: 4-7. 


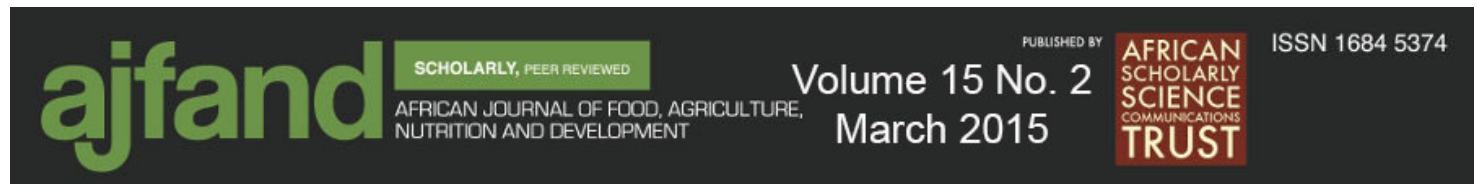

35 Mozaffarian D, Hao T, Rimm EB, Willett WC andFB Hu Changes in diet and lifestyle and long-term weight gain in women and men. N Engl J Med 2011; 364: 2392-2404.

36 Pérez-Jiménez F, López-Miranda J, Pinillos MD, Gómez P, Paz-Rojas E, Montilla P, Marín C, Velasco MJ, Blanco-Molina A, Jiménez Perepérez JA and JM Ordovás A Mediterranean and a high-carbohydrate diet improve glucose metabolism in healthy young persons. Diabetologia 2001; 44: 2038 2043.

37 Eshak ES, Iso H, Date C, Kikuchi S, Watanabe Y, Wada Y, Wakai K and A Tamakoshi Dietary fiber intake is associated with reduced risk of mortality from cardiovascular disease among Japanese men and women. $J$ Nutr 2010; 140: $1445-1453$.

38 Panigrahi A andPB Sahoo Nutritional anemia and its epidemiological correlates among women of reproductive age in an urban slum of Bhubaneswar, Orissa. Indian J Public Health 2011; 55:317-20.

39 Lanska DJ Chapter 30: historical aspects of the major neurological vitamin deficiency disorders: the water-soluble B vitamins. Handb Clin Neurol 2010; 95:445-76.

40 Prasad AS Impact of the discovery of human zinc deficiency on health. $J \mathrm{Am}$ Coll Nutr 2009; 28: 257-65.

41 Srinath Reddy $\mathbf{K}$ andMB Katan Diet, nutrition and the prevention of hypertensionand cardiovascular diseases. Public Health Nutr 2004; 7: 167-186.

42 Bánhidy F, Acs N, Puhó EH and AE Czeizel Iron deficiency anemia: pregnancy outcomes with or without iron supplementation. Nutrition 2011; 27: 65-72.

43 Trichopoulou A, Katsouyanni K and Gnardellis C The traditional Greek diet. Eur J Clin Nutr. 1993; (47S): 76-81. 